\title{
Factors Associated with Breastfeeding Practices among Mothers in Primary Health Care Sitting: A Cross-sectional Study
}

\author{
Abdulaziz Saleh Aljohani $^{1}$ and Kamal Abdulkarim Alnazzawi ${ }^{2}$ \\ 1. Department of Family Medicine, Security Forces Medical Services, Riyadh, Kingdome of Saudi Arabia \\ 2. Department of Pediatrics, Security Forces Medical Services, Riyadh, Kingdome of Saudi Arabia
}

\begin{abstract}
BACKGROUND: Appropriate infant and young child feeding practices are essential for optimal growth, cognitive development, and overall well-being in early vulnerable years of life. Malnutrition contributes to the majority of under-five mortality worldwide annually and over two-thirds of these are due to inappropriate feeding practices. This study aimed at determining the breastfeeding practice among mothers in primary health care sitting, examining the effect of some demographics and socio-economic factors on breastfeeding duration and at identifying the most important reasons that led mothers to stop breastfeeding and wean their children before two years. MATERIALS AND METHODS: A community-based cross-sectional study was conducted from January to March 2016. Participants was mothers having children less than five years of age attending the well baby clinic for immunizations, growth monitoring, treatment of minor illnesses, health check-ups, follow-up, and so forth were interviewed after taking an informed consent. The study relied on primary data collected through structured questionnaire designed to cover all research objectives. Descriptive as well as inferential statistics techniques were utilized. The statistical Package for Social Science (SPSS) was used to analyze the data. RESULTS: From the total of 294 mother-infant pairs, 166 were included in the analysis. The results revealed that the majority of the mothers 107 (64.5\%) breast natural breastfeeding for full four months. Also, 90 (54.2\%) of them initiated breastfeeding after one hour from delivery. It was clear that the main reason led the mothers to wean their infants was mother work 80 (48.2\%). Further the results suggested a significant association between breastfeeding duration and some variables such as age of the mother, mother occupation and pregnancy are all. CONCLUSION: The present work indicates that mothers' practices related to breastfeeding in the Primary Health Care clinics for the Security Forces are still not to optimum, efforts should be made to change breastfeeding behaviors not in line with recommendations and reinforce that in accordance with the recommendations. The study recommended encouraging breastfeeding and educating mothers and especially worker women.
\end{abstract}

Key words: Breastfeeding practice, primary health care, complimentary food and pregnancy

\section{Introduction}

Breastfeeding is defined as the process of feeding an infant or young child with milk from mother breasts. Babies have a suckling urge that enables them to take in the milk, provided there is a good latch, a normal frenulum, and milk supply [1]. It is only recently that modern scientific researches have brought to light the paramount importance of the breastfeeding to the health of child and mother. Several global and national

Corresponding author: Abdulaziz Saleh Aljohani, professor, research field: family medicine, palliative care and medical education. organizations [2-7], including UNICEIF and WHO acknowledge breastfeeding as the Gold Standard of infant feeding. In 1990, WHO and UNICEIF jointly adopted the Innocent declaration, on the protection, promotion and support of breastfeeding [8]. UNICEIF and WHO recommended that all mothers should breastfeed their babies exclusively for six months and continue breastfeeding complemented by other appropriate foods, up to the second year of life [9]. Breastfeeding is important not only for child health and survival but it is an important determinant of fertility, and mother health [10].

Evidence showed the increasing beneficial effects of 
breastfeeding, it provides the ideal food for normal growth and development of infant in term of nutrition, protection from diarrheal diseases [11-13], respiratory tract [14-17] and urinary tract infections [18], as well as neonatal infections [19]. It reduces the incidence of asthma and other atopic disease [20-22], it protects against obesity [23, 24] diabetes mellitus [25], hypertension, and hence vascular diseases [26]. Economically it reduces the population growth [10] and hospital cost of admission for respiratory infections and diarrheal diseases $[12,27]$. It promotes intelligence and cognitive development [28, 29]. In developing countries, children are suffered from high risk of death due to poor infant feeding and malnutrition. Nearly all women can breastfeed if they are supported to be confident and aware of good techniques and promotion of practices [29]. There are many factors which determine the breastfeeding practices and make women fail to complete the two years of breastfeeding. The main objectives of this study are to determine the breastfeeding practice among mothers in primary health care sitting, examining the effect of some demographics and socio-economic factors on breastfeeding duration and at identifying the most important reasons that led mothers to stop breastfeeding and wean their children before two years.

\section{Materials and Methods}

\subsection{Study Design}

A community-based cross-sectional study, using on both quantitative and qualitative methods of data collection.

\subsection{Study Site and Population}

This study was conducted at Primary Health Care clinics for the Security Forces (PHCSF) catering to children from birth to 18 years of age attached to a tertiary care Security Forces Hospital (SFH) located at Riyadh, capital of Saudi Arabia and one of the largest cities over a period of three months from January to March 2016. Mothers having children less than five years of age attending the well baby clinic for immunizations, growth monitoring, treatment of minor illnesses, health check-ups, follow-up, and so forth were interviewed after taking an informed consent. All children with known non nutritional congenital or acquired reasons (e.g., congenital heart diseases, cerebral palsy, genetic disorders, and tuberculosis) of failure to thrive were excluded.

\subsection{Study Procedure}

Quantitative data were collected using a validated questionnaire adapted from WHO global strategy for infant and young child feeding [30]. The questionnaire consisted of 30 structured questions on socio demographic variables, feeding practices, and morbidities of children (hospitalization, diarrhea, and acute respiratory illnesses). The questionnaire was in English but the interviews were conducted in local language (Arabic) as per mothers' convenience. The OPD runs between 8:00 a.m. and 12:30 p.m. and between 1:30 p.m. and 4:30 p.m. Interviews were conducted between 10 a.m. and 12:30 p.m. and each interview took approximate 15 to 20 minutes to finish. A simple random sampling technique was used with anticipated population on proportion estimated to yield a sample of 166 women to be investigated.

\subsection{Statistical Analysis}

After the set of data were collected using questionnaire, the data were coded and organized; the Statistical Package for social science (SPSS) was used to analyze the data. General tabulations including frequency distribution were used. Also chi-square test was used to test some associations between the dependent variable breastfeeding duration and a set of independent variables. More over multiple linear regression is utilized to study the determinants of the duration of breastfeeding practice.

\subsection{Ethical Consideration}

The study was approved by human research ethics 
committee of SFH for Medical Care and Education.

\section{Results}

From the total of 294 mother-infant pairs, 166 were included in the analysis. Table 1 shows occupational, educational status, distribution of mothers according to age groups, contraceptive use and contraceptives methods. It showed that 73 (44\%) of the women are housewives, $52(31.3 \%)$ are employees, $18(10.8 \%)$ are students and 23 (13.9\%) are business women. Regarding the educational status, it was found that, 69 $(41.5 \%)$ were secondary educated, 58 (35\%) university graduates, $24(14.5 \%)$ were intermediate, 11 (6.6\%) were primary and $4(2.4 \%)$ are illiterate. The relatively large percentages of mothers are in age groups from 25 to 40 years, which indicates a young age structure. The table also shows the distribution of mothers who are currently using family planning. The distribution showed that $94(56.6 \%)$ of them were current user, while not users were 72 (43.4\%). Further, the users were asked to determine the type of contraceptives. The majorities are using pills $71(42 \%)$, only $10(6 \%)$ and $9(5.4 \%)$ used safe period and injections respectively, while $1.8 \%$ of the mothers used Intra Uterine Device (IUD). Condoms were rarely used by the woman since only one woman is using condoms.

For breastfeeding practice, all mothers were asked when they initiated breastfeeding after child birth. The majority of them initiated breastfeeding after one hour from delivery $90(54.2 \%)$, and $66(39.7 \%)$ of them initiated breastfeeding during the period from two hours to 24 hours. Only $10(6.0 \%)$ of the mothers initiated breastfeeding after one day (Table 2). Table 2 also illustrated the distribution of natural breastfeeding practice as well as the duration of breast feeding in months. It is clear from the table that woman who exclusively breastfeeding for full four months are the majority, consisting 107 (64.5\%). Those who breastfeed for six months were 49 (29.5\%), while only $10(6.0 \%)$ breastfeed for two months. Table 2 also showed the distribution of breastfeeding duration. It is clear that the majority of the mothers stopped breastfeeding during the period between 19 to 24 months, $36(21.7 \%)$ of them stopped breastfeeding before one year and 40 (24.1\%) stopped breastfeeding during the period 13 to 18 months.

The study found that exclusive breastfeeding was ranged between four and six months because most mothers give their infants complementary food after six months $149(89.8 \%)$ and only $17(10.2 \%)$ after four months (Table 2).

Regarding food type, the majority of the mothers give their children traditional food more than 123 (74\%) while only 43 (26\%) of the women gave ready made food for their children. On the other hand 34 (20.5\%) of the mothers stated that they use bottle for their children (Table 2).

Table 1 Demographic characteristics of the mothers.

\begin{tabular}{lll}
\hline Characteristics & Number $(N)$ & Percentage (\%) \\
\hline Mother's occupation & & 31.3 \\
\hline Employer & 52 & 44 \\
Housewife & 73 & 10.8 \\
Student & 18 & 13.9 \\
Business Women & 23 & \\
\hline Mother's educational status & & 2.4 \\
\hline Illiterate & 4 & 6.6 \\
Primary & 11 & 14.5 \\
Intermediate & 24 & 41.5 \\
Secondary & 69 & 35 \\
University and above & 58 & \\
\hline Age of mothers (years) & & 2.4 \\
15-19 & 4 & 11.4 \\
20-24 & 19 & 23.5 \\
25-29 & 39 & 3.7 \\
30-34 & 51 & 24.1 \\
35-39 & 40 & 6 \\
40-44 & 10 & 1.8 \\
45-49 & 3 & 56.6 \\
\hline Contraceptive Use & & \\
\hline Yes & 94 & 6.4 \\
No & 72 & \\
\hline Contraceptive Types & & \\
\hline Pills & 71 & \\
Injections & 10 & \\
IUD & & \\
Condom & & \\
Safe period & & \\
\hline & & \\
\hline
\end{tabular}


Table 2 Breastfeeding Practice.

\begin{tabular}{lll}
\hline Characteristics & Number $(N)$ & Percentage (\%) \\
\hline Initiation of breastfeeding & & \\
\hline After one hour & 90 & 54.2 \\
Two hour to 23 hours & 66 & 39.8 \\
After one day & 10 & 6 \\
\hline Exclusive Breastfeeding & & \\
\hline Two months & 10 & 6 \\
Four months & 107 & 64.5 \\
Six months & 49 & 29.5 \\
\hline Duration of Breastfeeding & & \\
\hline 1-6 Months & 10 & 6 \\
7-12 Months & 26 & 15.7 \\
13-18 Months & 40 & 24.1 \\
19-24 Months & 80 & 48.2 \\
More than 24 Months & 10 & 6 \\
\hline Age for Complimentary Food & \\
\hline After four Months & 17 & 10.2 \\
After six Months & 149 & 89.8 \\
\hline Food Types & 123 & 74 \\
\hline Traditional food & 43 & 26 \\
Ready made food & 34 & 20.5 \\
\hline Bottle usage & 132 & 79.5 \\
\hline Used & & \\
Not used & & \\
\hline
\end{tabular}

Fig. 1 illustrates the main reasons which lead the mothers to stop breast feeding. It was clear that the main reason led the mothers to wean their infants was work 81 (48.2\%). Some mothers stopped breastfeeding their children because their health was not helpful to continue breastfeeding 29 (16.7\%). Others argued that they stopped breastfeeding for cultural beliefs 20 (11.2\%). Only 15 (8.2\%) stopped breastfeeding for less milk production and $11(6.2 \%)$ for pregnancy.

Variables associated with breastfeeding duration were measured. In each case, a test of independence was performed using $\chi^{2}$ (Chi-square) test of independency. The independent variables that assumed to affect the duration of breastfeeding (dependent variable) are age of mother, education of the mother, parity, mother's occupation, pregnancy and contraceptives use.

Table 3 shows that, age of the mother, mother occupation and pregnancy are all significant. This means that these variables are associated with the breastfeeding duration. On the other hand, mother's education, parity, contraceptive use turned out to be has no association with the duration of breastfeeding.

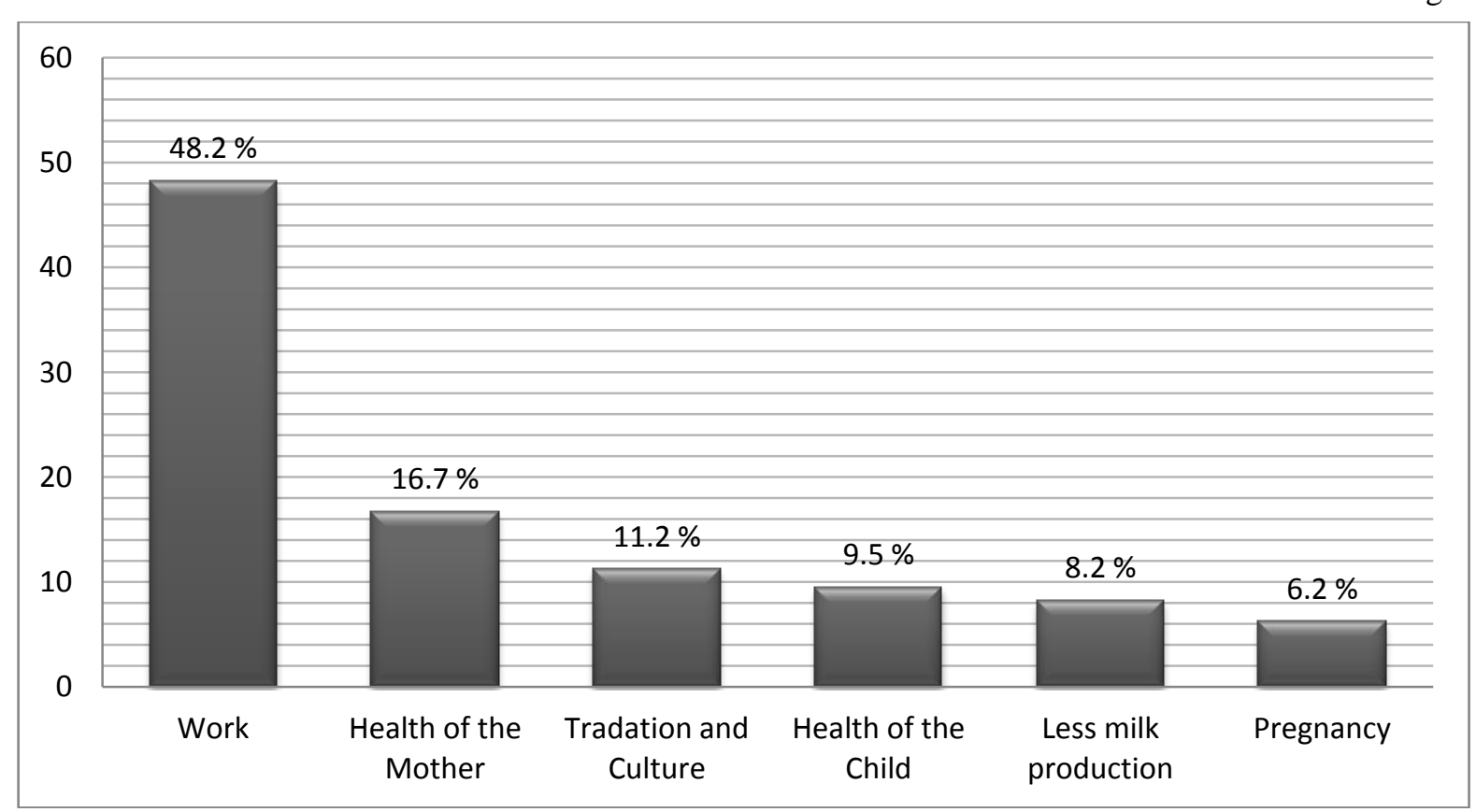

Fig. 1 Reasons for stopping breastfeeding. 
Table 3 Association between breastfeeding duration and some selected variables.

\begin{tabular}{lll}
\hline Independent Variable & $\chi^{2}$ Value & $P$ value \\
\hline Age of the mother & 127 & 0.0001 \\
Mother's education & 4.50 & 0.29 \\
Parity & 5.10 & 0.23 \\
Mother's occupation & 12.5 & 0.003 \\
Pregnancy & 6.96 & 0.04 \\
Contraceptive use & 2.13 & 0.34 \\
\hline
\end{tabular}

\section{Discussion}

Conventional wisdom supported by scientific research, advocates breastfeeding as superior method of infant feeding. The nutrition, immunological, psychological, and general health advantages conveyed to notes have been documented for years. The merits of human breast milk as compared to artificial feeds include ideal nutrition content, better absorption, fewer food related allergies, more favorable psychological development, better immunologic defenses, and a substantial economic advantage. There is another compelling benefit to exclusive breastfeeding: positive effects on the development of an infant's oral cavity, including improves shaping of the hard palate resulting in proper alignment of teeth and fewer problems with malocclusions [31, 32]. Breastfeeding is a natural impulse of all mothers as it allows them to express their love, tenderness and protection of their children.

WHO and UNICEIF have recommended initiation of breast feeding within the first hour of life. Exclusive breastfeeding for six months is recommended and should be continued with appropriate complementary food for two years [33].

Studying these factors, we found that $54.2 \%$ of mothers started breastfeeding their children within one hour which is similar to the result of Middle East and North Africa, Sub-Saharan Africa and Asian countries and higher than North America and Europe [34]. The importance of early initiation of breastfeeding come from the fact that early skin to skin contact is associated with more affectionate behavior of mother towards her infant that decrease the rate of breastfeeding problems [33]. The goal of desirable rate of exclusive breastfeeding is still not achieved in most of the developing countries. The exclusive breastfeeding rate for six month in our study is $29.4 \%$ which is lower than Latin America (31\%) and Asia (45\%) [35]. Factors that determine stoppage of breastfeeding in our study are headed by mother work $48.2 \%$ which is differ from Europe and North America where the main determinant factor is the decision of the mother to breast feed her child [36, 37]. Bottle feeding carries a significant risk of morbidity because of bottle contamination, and is therefore a useful indicator to follow. Bottle feeding is highly variable depending on the region. It is lowest in Sub-Saharan Africa, although it is $30 \%$ in Namibia and Nigeria. In Latin America and Caribbean, breastfeeding rates are very high while much lower in Asia (9.2\%) [37, 38]. In our study, bottle feeding is about $20.5 \%$ which is similar to Sub-Saharan Africa, and Near East/North Africa [38]. In our study, most mothers used to give their children home made food, which is good, but they need to be counseled to fit with the national recommendations.

\section{Conclusion}

When looking into the breastfeeding issue from a more anthropological-social point of view, we observe that the cultural practices and beliefs prevailing in a society are the ones that determine to a considerable degree which procedure will be considered natural and, therefore, accepted by people.

Health education programmers for breastfeeding promotion should address the barriers for achieving high rates of breastfeeding indicators. Working mothers should be encouraged by providing facilities for breastfeeding in the work place paid maternal leave for six months to achieve exclusive breastfeeding. WHO/UNICEF, Baby Friendly Hospital Initiative must be adopted in all maternity and pediatrics hospital. Universities can introduce breastfeeding promotion as part of community courses. 


\section{Acknowledgment}

The authors acknowledge Ms. Mary Bath for her effort and advice regarding the final review.

\section{References}

[1] World Health Organization. 1998. "Postpartum Care of the Mother and Newborn." Document number WHO/RHT/MSM/98.3. Geneva.

[2] World Health Organization. 1999. WHO Report IMCI. Accessed October 30, 2015. http://www.who.int/.

[3] World Alliance for Breastfeeding Action. 2002. Global Forum 2: Challenges to Breastfeeding in the 21st Century, Arusha, Tanzania.

[4] World Alliance for Breastfeeding Action. 2015. "World Breastfeeding Week 1-7 August 2015." Accessed October 30, 2015. http://www.waba.org.my/.

[5] International Baby Food Action Network. 2006. African News. Accessed October 30, 2015. http://www.ibfan-africa.org/.

[6] International Baby Food Action Network. 2000. Africa Maternity Protection. Accessed October 30, 2015. http://www.ibfan-africa.org/.

[7] World Alliance for Breastfeeding Action. 2015. Breastfeeding Healthy Mothers and Healthy Babies. Accessed October 30, 2015. http://www.waba.org.my/.

[8] World Health Organization. 1989. Protecting, Promoting and Supporting Breastfeeding: The Special Role of Maternity Services. A Joint WHO/ UNICEIF Statement. Geneva: World Health Organization.

[9] WHO and UNICEIF. 1990. Innocenti Declaration on the Protection, Promotion and Support of Breastfeeding. Florence, Italy.

[10] Labbok, M., Cooney, K., and Coly, S. 1994. Guidelines: Breastfeeding, Family Planning, and the Lactational Amenorrhea Method-LAM. Washington, DC: Institute for Reproductive Health/Georgetown University.

[11] WHO Collaborative Study Team on the Role of Breastfeeding on the Prevention of Infant Mortality. 2000. "Effect of Breastfeeding on Infant and Child Mortality due to Infectious Diseases in Less Developed Countries: A Pooled Analysis.” Lancet 355 (9202): 451-5.

[12] De Zoysa, I., Rea, M., and Martines, J. C. 1991. "Why Promote Breastfeeding in Diarrheal Disease Control Programs?" Health Policy and Planning 6 (4): 371-9.

[13] Khin, M. U., Wai, N. N., Khin, M., Khin, M. M., Tin, U., and Toe, T. 1985. "Effect on Clinical Outcome of Breast Feeding during Acute Diarrhea." British Medical Journal (Clinical Research Ed.) 290 (6468): 587-9.

[14] César, J. A., Victora, C. G., Barros, F. C., Santos, I. S., and Flores, J. A. 1999. "Impact of Breast Feeding on
Admission for Pneumonia during post-Neonatal Period in Brazil: Nested Case-Control Study." BMJ 318 (7194): 1316-20.

[15] Bachrach, V. R., Schwarz, E., and Bachrach, L. R. 2003. "Breastfeeding and the Risk of Hospitalization for Respiratory Disease in Infancy: A Meta-Analysis." Archives of Pediatrics and Adolescent Medicine 157 (3): 237-43.

[16] Howie, P. W., Forsyth, J. S., Ogston, S. A., Clark, A., and Florey, C. D. 1990. "Protective Effect of Breast Feeding against Infection.” BMJ 300 (6716): 11-6.

[17] Wilson, A. C., Forsyth, J. S., Greene, S. A., Irvine, L., Hau, C., and Howie, P. W. 1998. "Relation of Infant Diet to Childhood Health: Seven Year Follow Up of Cohort of Children in Dundee Infant Feeding Study." BMJ 316 (7124): 21-5.

[18] Ashraf, R. N., Jalil, F., Zaman, S., Karlberg, J., Khan, S. R., Lindblad, B. S., and Hanson, L. A. 1991. "Breast Feeding and Protection against Neonatal Sepsis in a High Risk Population." Archives of Disease in Childhood 66 (4): 488-90.

[19] Gdalevich, M., Mimouni, D., and Mimouni, M. 2001. "Breast-Feeding and the Risk of Bronchial Asthma in Childhood: A Systematic Review with Meta-Analysis of Prospective Studies.” Journal of Pediatrics 139 (2): 261-6.

[20] Kull, I., Wickman, M., Lilja, G., Nordvall, S. L., and Pershagen, G. 2002. "Breast Feeding and Allergic Diseases in Infants-a Prospective Birth Cohort Study." Archives of Disease in Childhood 87 (6): 478-81.

[21] Saarinen, U. M., and Kajosaari, M. 1995. "Breastfeeding as Prophylaxis against Atopic Disease: Prospective Follow-up Study until 17 Years Old." Lancet 346 (8982): 1065-9.

[22] von Kries, R., Koletzko, B., Sauerwald, T., von Mutius, E., Barnert, D., Grunert, V., and von Voss, H. 1999. "Breast Feeding and Obesity: Cross Sectional Study." BMJ 319 (7203): 147-50.

[23] Gillman, M. W., Rifas-Shiman, S. L., Camargo, C. A. Jr., Berkey, C. S., Frazier, A. L., Rockett, H. R., Field, A. E., and Colditz, G. A. 2001. "Risk of Overweight among Adolescents Who Were Breastfed as Infants." Journal of the American Medical Association 285 (19): 2461-7.

[24] Work Group on Cow's Milk Protein and Diabetes Mellitus. 1994. "Infant Feeding Practices and Their Possible Relationship to the Etiology of Diabetes Mellitus." Pediatrics 94 (5): 752-4.

[25] Singhal, A., Cole, T. J., and Lucas, A. 2001. "Early Nutrition in Preterm Infants and Later Blood Pressure: Two Cohorts after Randomised Trials.” Lancet 357 (9254): 413-9.

[26] Arifeen, S., Black, R. E., Antelman, G., Baqui, A., Caulfield, L., and Becker, S. 2001. "Exclusive 


\section{Primary Health Care Sitting: A Cross-sectional Study}

Breastfeeding Reduces Acute Respiratory Infection and Diarrhea Deaths among Infants in Dhaka Slums." Pediatrics 108 (4): E67.

[27] Mortensen, E. L., Michaelsen, K. F., Sanders, S. A., and Reinisch, J. M. 2002. "The Association between Duration of Breastfeeding and Adult Intelligence." Journal of the American Medical Association 287 (18): 2365-71.

[28] WHO. 2003. "Global Strategy on Infant and Young Child Feeding." World Health Organization, Geneva, Switzerland.

[29] Anderson, J. W., Johnstone, B. M., and Remley, D. T. 1999. "Breast-Feeding and Cognitive Development: A Meta-Analysis." American Journal of Clinical Nutrition 70 (4): 525-35.

[30] Palmer, B. 1998. "The Influence of Breastfeeding on the Development of the Oral Cavity: A Commentary." Journal of Human Lactation 14 (2): 93-8.

[31] Drane, D. 1996. "The Effect of Use of Dummies and Teats on Orofacial Development." Breastfeeding Review 4 (2): 59-64.

[32] Harmon-Jones, C. 2006. "Duration, Intensity, and Exclusivity of Breastfeeding: Recent Research Confirms the Importance of These Variables." Breastfeeding Abstracts 25 (3): 17-20.
[33] UNICEF. 2015. Desirable Rate of Exclusive Breastfeeding, still a Distant Goal in Most of the Arab World. Accessed October 30 , 2015. http://www.unicef.org/media/media_82715.html.

[34] Stalteri, O. L. 2007. Comparison of the Factors that Influence Breastfeeding Duration in Selected Cultures. Accessed October 30, 2015. http:// www.epidemiology.vcu.edu/ MPH_progra $\mathrm{m} /$ Research/Stalteri.htm.

[35] Hajian-Tilaki, K. O. 2005. "Factors Associated with the Pattern of Breastfeeding in the North of Iran." Annals of Human Biology 32 (6): 702-13.

[36] Kamel, N. M., Ibrahim, A. G., Aref, S. R., and Ziyo, F. Y. 1997. "Current Status of Breastfeeding in Alexandria Governorate: A Community-Based Study." Eastern Mediterranean Health Journal 3 (3): 511-8.

[37] al-Mazroui, M. J., Oyejide, C. O., Bener, A., and Cheema, M. Y. 1997. "Breastfeeding and Supplemental Feeding for Neonates in Al-Ain, United Arab Emirates." Journal of Tropical Pediatrics 43 (5): 304-6.

[38] Peters, E., Wehkamp, K. H., Felberbaum, R. E., Krüger, D., and Linder, R. 2006. "Breastfeeding Duration Is Determined by Only a Few Factors." European Journal of Public Health 16 (2): 162-7. 